\title{
In Situ TEM Observations on Morphological Instability of Ultrathin Pb Film
}

\author{
L.H. Zhang, M.L. Sui, L. Zhang, and D.X. Li
}

Shenyang National Laboratory for Materials Science, Institute of Metal Research, Chinese Academy of Sciences, Shenyang 110016, P.R. China

Thin films with the thickness in the nanometer scale have drawn increasingly interests owing to their widespread applications. As there is a large volume fraction of the interfaces and surfaces in the ultrathin film systems, the total free energy of the systems is in a higher level and there is a driving force for the systems to change the shape to minimize the total free energy. Therefore, the ultrathin films are in metastable state. So, it is necessary to investigate the microstructural stability of the thin film systems. In this work, the spheroidization of the ultrathin $\mathrm{Pb}$ films and the subsequent coalescence of $\mathrm{Pb}$ particles under electron beam irradiation were investigated by using in situ transmission electron microscopy (TEM). The mechanism of spheroidization and coalescence were also discussed. $\mathrm{A} \mathrm{Pb} / \mathrm{Al}$ bilayer film with free surface of $\mathrm{Pb}$ was prepared by cold rolling $\mathrm{Al} / \mathrm{Pb} / \mathrm{Al}$ multilayer and ion milling technology.

It was found in TEM that the ultrathin $\mathrm{Pb}$ films are spheroidized under irradiation of electron beam, as shown in figure $1(\mathrm{a})$. While the $\mathrm{Pb}$ films with parallel-cubic orientation relationship to Al film have not changed the morphology even under long time irradiation, as shown in figure 1 (b). The collision and coalescence of the $\mathrm{Pb}$ particles were happened during the random walk of the small particles on the $\mathrm{Al}$ film after spheroidization of $\mathrm{Pb}$ film. The particles grew up in the way of coalescence. Figure 2 shows the serial in situ TEM images of the $\mathrm{Pb}$ particles recorded after spheroidization of $\mathrm{Pb}$ film. It can be seen that $\mathrm{Pb}$ particles, indicated by $\mathrm{A}, \mathrm{B}, \mathrm{C}, \mathrm{D}$, arrows 1 and 2, grew up in the way of coalescence with prolonging the irradiation time. The time from contact of two particles to the end of coalescence will last for about 20 minutes.

Thermodynamic analysis indicated that the morphological instability of thin films depends on the microstructure of interfaces and therefore the interfacial energy. The smaller interfacial energy of the $\mathrm{Pb} / \mathrm{Al}$ semicoherent interface is favorable for stabilizing the $\mathrm{Pb}$ thin films under electron beam irradiation ${ }^{[1]}$. The coalescence of $\mathrm{Pb}$ particles is due to the large surface of particles when they just touch each other. So, driving force for the morphological change was to minimize the total energy by lowering the non-epitaxial $\mathrm{Pb} / \mathrm{Al}$ interfacial area in the spheroidization process and reducing the $\mathrm{Pb}$ surface in the particle coalescence. The intensive motion of the surface atoms ${ }^{[2]}$ for the $\mathrm{Pb}$ films and particles under irradiation activated the morphological instability of the system ${ }^{[3]}$.

\section{References}

[1] L.H.Zhang et. al. Appl. Phys. Lett., 78(2001), 3621.

[2] C. R. Stoldt et al.,,Phys. Rev. Lett., 81(1997), 2950.

[3] This research was supported by National Natural Science Foundation of China. 

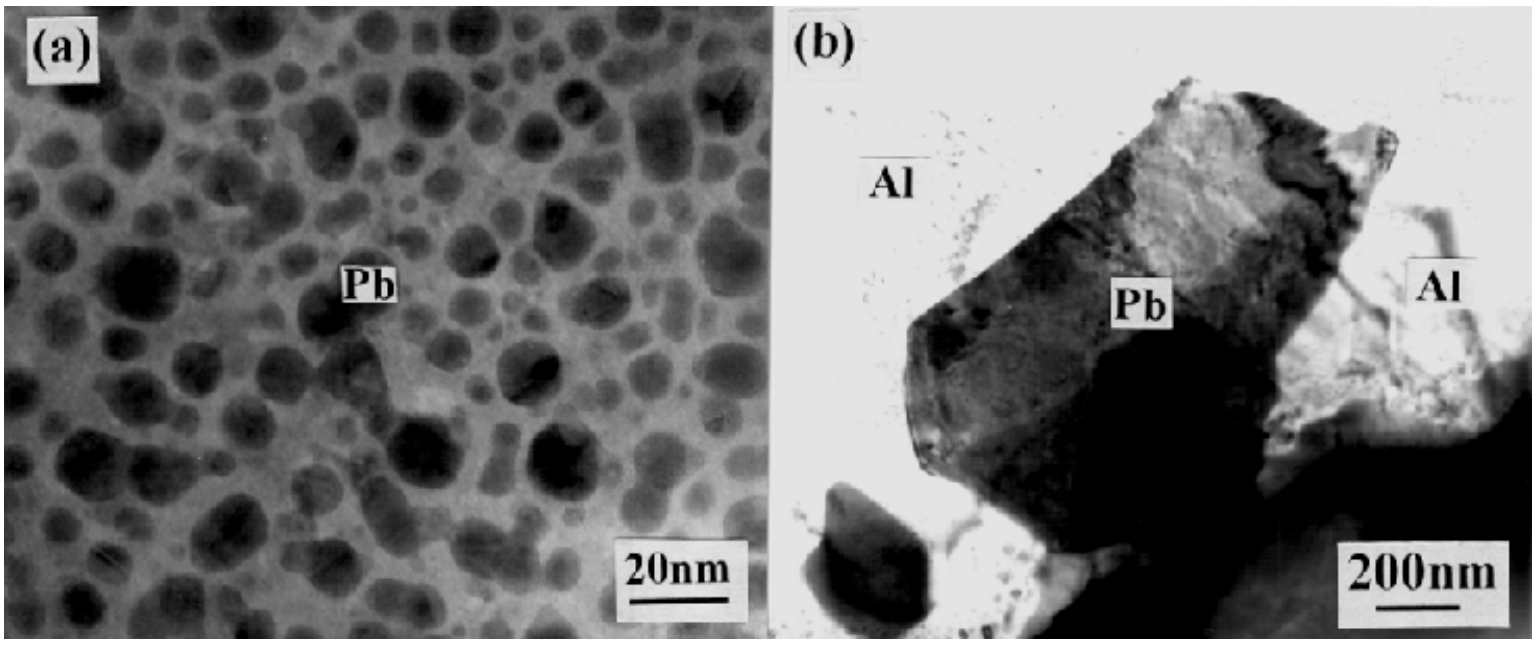

Fig. 1 The TEM bright-field images of spheroidized $\mathrm{Pb}$ film (a) with no orientation relationship to $\mathrm{Al}$ film and the stable $\mathrm{Pb}$ film with orientation relationship to $\mathrm{Al}$ film (b).

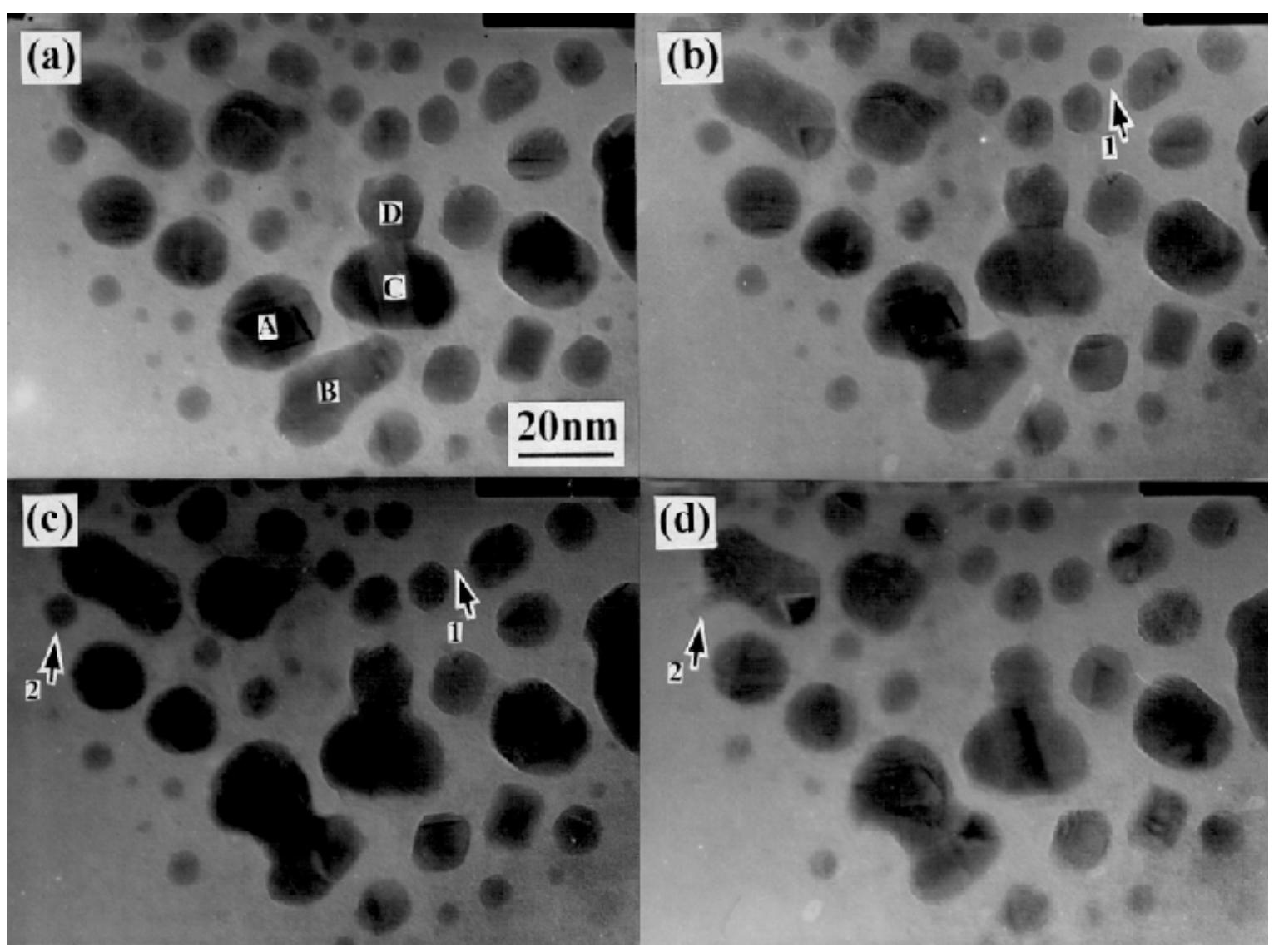

Fig. 2 Sequential in situ TEM images of $\mathrm{Pb}$ particles that coalesce each other at different interval. a) $\mathrm{t}=0 \mathrm{~s}, \mathrm{~b}) \mathrm{t}=20 \mathrm{~s}, \mathrm{c}) \mathrm{t}=40 \mathrm{~s}, \mathrm{~d}) \mathrm{t}=140 \mathrm{~s}$. 